\title{
INTERNALISASI NILAI-NILAI PENDIDIKAN KARAKTER DI MADRASAH
}

\author{
Muhammad Isnaini \\ Dosen Fakultas Tarbiyah, Ketua Badan Penelitian dan Pengembangan Pendidikan Islam (BP3i) \\ Fakultas Tarbiyah IAIN Raden Fatah Palembang \\ Email: isnain_m@yahoo.co.id
}

\begin{abstract}
Character education is a positive offer in the eradication of moral crises which particularly emerged in our students. Therefore, the internalization of values of character education in the educational institution is a must. As an Islamic education institution in Indonesia, the existence of Boarding school is considered to be able to develop values of character education which may be done through formal or non-formal curriculum. This is so because since its early existence, Boarding school has delineated its distinctive feature which is different from the other common types of education. Here, the implementation of character values have been integrated (within large portion) in the religious subjects.
\end{abstract}

Key words: boarding school, values, character education

\begin{abstract}
Abstrak: Pendidikan karakter merupakan tawaran yang positif dalam mengatasi krisis moral yang tengah melanda generasi muda khususnya kalangan pelajar. Oleh karena itu, internalisasi nilai-nilai pendidikan karakter di lembaga pendidikan merupakan suatu keharusan. Madrasah sebagai salah satu lembaga pendidikan Islam di Indonesia merupakan salah satu solusi cerdas dalam mengembangkan nilai-nilai pendidikan karakter baik melalui kurikulum formal maupun non formal, karena sejak awal berdirinya Madrasah sudah menunjukkan ciri khasnya yang berbeda dari lembaga pendidikan pada umumnya, dimana penanaman nilai karakter sudah terintegrasi dalam mata pelajaran agama yang memiliki porsi cukup besar.
\end{abstract}

Kata Kunci: Madrasah, Nilai-nilai pendidikan karakter

\section{PENDAHULUAN}

Krisis moral yang saat ini melanda generasi muda, acapkali menjadi apologi bagi sebagian orang untuk memberikan kritik pedasnya terhadap institusi pendidikan. Hal tersebut teramat wajar karena pendidikan sesungguhnya memiliki misi yang amat mendasar yakni membentuk manusia seutuhnya dengan akhlak mulia sebagai salah satu indikator utama, generasi bangsa dengan karatekter akhlak mulia merupakan salah satu profil yang diharapkan dari praktek pendidikan nasional. UU No. 20 tahun 2003 bab II pasal 3 tentang fungsi dan tujuan pendidikan nasional bahwa pendidikan nasional berfungsi mengembangkan kemampuan dan membentuk watak serta peradaban bangsa yang bermartabat dalam rangka mencerdaskan kehidupan bangsa bertujuan untuk berkembangnya potensi peserta didik agar menjadi manusia yang beriman dan bertakwa kepada Tuhan Yang Maha Esa, berakhlak mulia, sehat, berilmu, cakap, kreatif, mandiri dan menjadi warga negara yang demokratis serta bertanggung jawab.

Berbagai fenomena yang mengkhawatirkan saat ini banyak bermunculan di media masa baik televisi, Koran, dan lain-lain. Fenomena tersebut diantaranya bisa kita simak dari berita yang dipublikasikan berbagai media seringkali membuat kita miris mendengarnya, perkelahian antar pelajar, pergaulan bebas, kasus narkoba di kalangan pelajar, remaja usia sekolah yang melakukan perbuatan amoral, kebut-kebutan di jalanan yang dilakukan remaja usia sekolah, menjamurnya geng motor yang beranggotakan remaja usia sekolah, siswa bermain di pusat perbelanjaan pada saat jam pelajaran, hingga siswa Sekolah Dasar (SD) yang merayakan kelulusan dengan pesta minuman keras.

Krisis yang melanda pelajar (juga elite politik) mengindikasikan bahwa pendidikan agama dan moral yang didapat di bangku sekolah, tidak berdampak terhadap perubahan 
perilaku manusia Indonesia. Bahkan yang terlihat adalah begitu banyak manusia Indonesia yang tidak koheren antara ucapan dan tindakannya. Kondisi demikian, diduga berawal dari apa yang dihasilkan oleh dunia pendidikan. (Zubaidi, 2011: 2).

Indikator lain yang menunjukkan adanya gejala rusaknya karakter generasi bangsa bisa dilihat dari praktek sopan santun siswa yang kini sudah mulai memudar, diantaranya dapat dilihat dari cara berbicara sesama mereka, prilakunya terhadap guru dan orangtua, baik di sekolah maupun di lingkungan masyarakat, kata-kata kotor yang tidak sepantasnya diucapkan oleh anak seusianya seringkali terlontar. Sikap ramah terhadap guru ketika bertemu dan penuh hormat terhadap orangtua pun tampaknya sudah menjadi sesuatu yang sulit ditemukan di kalangan anak usia sekolah dewasa ini. Anakanak usia sekolah seringkali menggunakan bahasa yang jauh dari tatanan nilai budaya masyarakat. Bahasa yang kerap digunakan tidak lagi menjadi ciri dari sebuah bangsa yang menjunjung tinggi etika dan kelemahlembutan.

Melihat fenomena yang terjadi diatas, maka lembaga Pendidikan memiliki peran yang sangat besar dalam membentuk karakter anak. Salah satu lembaga pendidikan yang memberikan perhatian besar dalam membentuk karakter anak adalah Madrasah, karena Madrasah memiliki cirri khusus yang berbeda dari lembaga pendidikan umum, dimana muatan-muatan nilai agama memiliki porsi yang cukup banyak dalam membentuk dan mengembangkan karakter anak.

\section{PENDIDIKAN KARAKTER DALAM ISLAM}

Pengertian karakter adalah watak, tabiat, pembawaan, kebiasaan. Karakter adalah cara berpikir dan berperilaku yang menjadi ciri khas individu untuk hidup dan bekerjasama, baik dalam lingkup keluarga, masyarakat, bangsa dan Negara. Menurut bahasa, karakter adalah tabiat atau kebiasaan. Sedangkan menurut ahli psikologi, karakter adalah sebuah system keyakinan dan kebiasaan yang mengarahkan tindakan seorang individu. Karena itu, jika pengetahuan mengenai karakter seseorang itu dapat diketahui, maka dapat diketahui pula bagaimana individu tersebut akan bersikap untuk kondisi-kondisi tertentu.

Dalam kamus besar Bahasa Indonesia, karakter diartikan sebagai sifat-sifat, kejiwaan, akhlak atau budi pekerti yang menjadi cirri khas seseorang. (M. Zulfajri dan Ratu Aprilia Senja, 2003: 422). Raymond mengartikan karakter dalam istilah psikologi dengan: "Character as the habitual mode a bringing into harmony the tasks presented by internal demand and by the external word, it is nessecarily a fungtion of the constant, organized and integrating part of the personality wich is called ago". (Raymond J Corsiny, 1994: 212). Adapun Hernowo mengartikan karakter sebagai watak, sifat atau hal-hal yang sangat mendasar pada diri seseorang. Karakter juga bisa diartikan sebagai watak, tabiat atau akhlak yang membedakan seseorang denan orang lain. (Hernowo, 2004: 175).

Pengertian karakter diatas sama dengan pengertian akhlak dalam pandangan Islam. Akhlak adalah sifat yang muncul dari jiwa seseorang untuk melakukan perbuatan secara tidak sadar dan tanpa peertimbangan terlebih dahulu. Beberapa tokoh yang memberikan pengertian akhlak antara lain adalah Imam Ghazali yang memaknai akhlak sebagai sifat yang tertanam dalam jiwa yang melahirkan berbagai macam perbuatan dengan mudah tanpa memerlukan pemikiran dan pertimbangan. (Imam Ghazali, tt: 56). Menurut Anis Matta akhlak adalah nlai yang telah menjadi sikap mental yang mengakar dalam jiwa, lalu tampak dalam bentuk tindakan dan perilaku yang bersifat tetap, natural dan reflek. (M. Anis Matta, 2006: 14). Perbuatan seseorang akan menjadi karakter atau akhlak jika dilakukan berulangulang dan menjadi kebiasaan dalam perilaku kehidupannya sehari-hari.

Pendidikan karakter adalah pendidikan budi pekerti plus, yaitu yang melibatkan aspek pengetahuan (cognitive), perasaan (feeling), dan tindakan (action). Menurut Thomas Lickona, tanpa ketiga aspek ini, maka pendidikan karakter tidak akan efektif. Dengan pendidikan karakter yang diterapkan secara sistematis dan berkelanjutan, seorang anak akan menjadi cerdas emosinya. Kecerdasan emosi ini adalah bekal penting dalam mempersiapkan anak 
menyongsong masa depan, karena seseorang akan lebih mudah dan berhasil menghadapi segala macam tantangan kehidupan, termasuk tantangan untuk berhasil secara akademis. (Thomas Lickona, E Shapes dan C. Lewis, 2003: 2)

Pendidikan karakter dapat dimaknai sebagai proses penanaman nilai-nilai esensial pada diri anak melalui serangkaian kegiatan pembelajaran dan pendampingan sehingga para siswa sebagai individu mampu memahami, mengalami, dan mengintegrasikan nilai-nilai yang menjadi core values dalam pendidikan yang dijalaninya kedalam kepribadiannya. Dengan menempatkan pendidikan karakter dalam kerangka dinamika dan dialektika proses pembentukan individu, para insan pendidik diha-rapkan emakin dapat menyadari pentingnya pendidikan karakter sebagai sarana pembentuk pedoman perilaku, pembentukan akhlak, dan pengayaan nilai individu dengan cara menyediakan ruang bagi figur keteladanan dan menciptakan sebuah lingkungan yang kondusif bagi proses pertumbuhan, berupa kenyamanan dan keamanan yang membantu suasana pengembangan diri satu sama lain dalam keseluruhan dimensinya (teknis, intelektual, psikologis, moral, sosial, estetis, dan religius).

Pendidikan karakter dapat dimaknai sebagai sebuah usaha untuk mendidik anak-anak agar dapat mengambil keputusan dengan bijak dan memperaktekannya dalam kehidupan sehari-hari, sehingga mereka dapat memberikan kontribusi yang positif kepada lingkungannya. Adapun nilai yang layak diajarkan kepada anakanak, dirangkum Indonesia Heritage Fondation (IHF) yang digagas oleh Ratna Megawangi menjadi sembilan pilar karakter (Arismantono, 2008: 29) yaitu;

1. Cinta tuhan dan Segenap Ciptaan-Nya (love Allah, trust, reverence, loyalty)

2. Kemandirian dan Tanggug Jawab (responsibility, excellence, self reliance, Discipline, orderliness)

3. Kejujuran dan Amanah, Bijaksana (trustworthiness, reliability, honesty)

4. Hormat dan Santun (respect, courtesy, obedience)
5. Dermawan, suka menolong dan Gotong Royong (love, compassion, caring, empathy, generousity, moderation, cooperation)

6. Percaya Diri, Kreatif, dan Pekerja keras (confidence, assertiveness, creativity, determination, and enthusiasm)

7. Kepemimpinan dan Keadilan (justice, fairness, mercy, leadership)

8. Baik dan Rendah Hati (kindness, friendliness, humality, modesty)

9. Toleransi dan Kedamaian dan kesatuan (tolerance, flexibility, peacefulness)

Dalam konteks Pendidikan Islam, karakter atau akhlak yang ditanamkan pada anak harus berlandaskan pada dua dimensi kehidupan manusia yaitu dimensi ke-Tuhanan dan dimensi kemanusiaan. (Nurcholis Majid, 2000: 96). Kedua dimensi ini perlu ditanamkan ke dalam diri seorang anak agar anak memiliki rasa ketakwaan kepada Allah swt dan rasa kemanusiaan terhadap sesama manusia, sehingga hablumminallah dan hablumminannas nya terpelihara dan terjaga.

Dimensi Ketuhanan atau yang dikenal dengan istilah nilai Robbaniyah akan melahirkan nilai-nilai kegamaan yang mendasar bagi kehidupan manusia yang amat penting ditanamkan pada anak. Nilai tersebut antara lain, iman, ikhsan, takwa, tawakkal, syukur, ikhlas dan sabar. (Nurcholis Majid, 2000: 88), Sedangkan dimensi kemanusiaan melahirkan nilai-nilai luhur (akhlakul akrimah) yang diwujudkan secara nyata dalam kehidupan sehari-hari. Nilai tersebut antara lain silaturrahmi, persamaan, keadilan, baik sangka, jujur dan lain-lain. (Nurcholis Majid, 2000: 101).

\section{MADRASAH SEBUAH SOLUSI BAGI PENDIDIKAN KARAKTER}

Madrasah adalah salah satu lembaga pendidikan Islam yang penting di Indonesia selain pesantren. Keberadaannya begitu penting dalam menciptakan kader-kader bangsa yang berwawasan keislaman dan berjiwa nasionalisme yang tinggi. Salah satu kelebihan yang dimiliki madrasah adalah adanya integrasi ilmu 
umum dan ilmu agama. Madrasah merupakan lembaga pendidikan yang dikelola secara terstruktur dengan melibatkan komponen-komponen pendidikan seperti manajemen, biaya, sarana dan prasarana, kruikulum, peserta didik, dan pendidik. Madrasah dibangun sebagai wahana pendidikan formal dalam rangka meningkatkan pengetahuan, keterampilan, sikap dan nilai peserta didik. Sebagai suatu sistem sosial, madrasah dapat dipandang sebagai organisasi yang interaktif dan dinamis, sebab di dalamnya terdapat sejumlah orang yang memiliki kepentingan yang sama (kepentingan penyelenggaraan pendidikan), tetapi kemampuan setiap individu pada komunitas itu memiliki potensi dan latar belakang yang berbeda.

Madrasah merupakan salah satu bentuk lembaga Pendidikan Islam yang berfungsi merealisasikan cita-cita umat Islam yang mengharapkan anak-anaknya menjadi manusia yang berimtak dan beriptek. Sebagai institusi pendidikan formal, Madrasah berperan dalam mempersiapkan siswa untuk dapat memecahkan masalah kehidupan masa kini dan masa datang dengan memaksimalkan potensi-potensi yang ada pada dirinya. Atas dasar tersebut, maka madrasah wajib menyelenggarakan proses pembelajaran dengan baik dengan memperhatikan berbagai faktor penunjangnya.

Dalam perkembangannya, madrasah yang tadinya hanya dipandang sebelah mata, secara perlahan-lahan telah berhasil mendapat perhatian dari masyarakat. Apresiasi ini menjadi modal besar bagi madrasah untuk memberikan yang terbaik bagi bangsa. Dalam konteks kekinian, sekarang ini banyak sekali madrasahmadrasah yang menawarkan konsep pendidikan modern. Konsep ini tidak hanya menawarkan dan memberikan pelajaran atau pendidikan agama. Akan tetapi mengadaptasi mata pelajaran umum yang diterapkan di berbagai sekolah umum. Kemajuan madrasah tidak hanya terletak pada sdm-nya saja, namun juga desain kurikulum yang lebih canggih, dan sistem manajerial yang modern. Selain itu, perkembangan kemajuan madrasah juga didukung dengan sarana infrastruktur dan fasilitas yang memadai sesuai dengan kebutuhan kegiatan belajar-mengajar di madrasah.
Untuk menumbuh kembangkan Pendidikan Islam atau Ilmu pendidikan Islam perlu telaah lebih jauh lagi, mengintegrasikan pengembangan Ilmu dengan wahyu (Chabib Thoha, dkk. 1996: 193). Pijakan awal berkenaan dengan pendidikan Islam adalah faktor yang secara eksplisit membedakan Ilmu Pendidikan Islam dengan ilmu-ilmu lainya ialah faktor nilai. (ChabibThoha, dkk. 1996: 289).

Pendidikan yang berlandaskan ilmu-ilmu ke-Islam-an yang mampu mensinerjikan berbagai disiplin ilmu yang menghasilkan kemajuan baik dibidang ilmu pengetahuan itu sendiri, sosial, budaya, politik dan masih banyak lagi kemajuan yang ditimbulkan. dan pendidikan yang demikian bisa didapatkan dalam lingkup madrasah.

\section{INTERNALISASI NILAI-NILAI PENDI- DIKAN KARAKTER DI MADRASAH}

Fenomena semakin menurunnya karakter bangsa juga menjadi tantangan tersendiri bagi madrasah. Terlebih madrasah mengusung model pendidikan dengan kelebihan subjek metter agama sebagai identitas. Minimnya jam belajar agama di sekolah umum yang seringkali disinyalir sebagai salah satu penyebab rusaknya moral anak bangsa, bagi madrasah terbantahkan. Di madrasah setidaknya memiliki 8 jam pelajaran agama (4 mata pelajaran pendidikan agama Islam) yakni Aqidah Akhlak, Al Qur'an Hadits, Fiqih, dan Sejarah Kebudayaan Islam.

Madrasah merupakan lembaga pendidikan yang dikelola secara terstruktur dengan melibatkan komponen-komponen pendidikan seperti manajemen, biaya, sarana dan prasarana, kurikulum, peserta didik, dan pendidik. Madrasah dibangun sebagai wahana pendidikan formal dalam rangka meningkatkan pengetahuan, keterampilan, sikap dan nilai peserta didik. Sebagai suatu sistem sosial, madrasah dapat dipandang sebagai organisasi yang interaktif dan dinamis, sebab di dalamnya terdapat sejumlah orang yang memiliki kepentingan yang sama (kepentingan penyelenggaraan pendidikan), tetapi kemampuan setiap individu 
pada komunitas itu memiliki potensi dan latar belakang yang berbeda.

Para ahli pendidikan karakter melihat proses internalisasi nilai dalam pembelajaran, termasuk internalisasi pendidikan karakter di Madrasah pada dua pendekatan. Pertama, Madrasah secara terstruktur mengembangkan pendidikan karakter melalui kurikulum formal. Kedua, pendidikan karakter berlangsung secara alamiah dan sukarela melalui jalinan hubungan interpersonal antar warga madrasah, meski hal ini tidak diatur secara langsung dalam kurikulum formal.

Kurikulum merupakan rencana tertulis yang berisi tentang ide-ide dan gagasan-gagasan yang dirumuskan oleh pengembang kurikulum. Kurikulum dapat diartikan sebagai sebuah dokumen perencanaan yang berisi tujuan yang harus dicapai, isi materi dan pengalaman belajar yang harus dilakukan peserta didik, strategi dan cara yang dapat dikembangkan, evaluasi yang dirancang untuk mengumpulkan informasi tentang pencapaian tujuan, serta implementasi dari dokumen yang dirancang dalam kehidupan nyata. Komponen-komponen kurikulum saling berkaitan dan saling mempengaruhi, terdiri dari tujuan yang menjadi arah pendidikan, komponen pengalaman belajar, komponen strategi pencapaian tujuan, dan komponen evaluasi. (Sanjaya, 2010: 16). Kurikulum berfungsi sebagai pedoman yang memberikan arah dan tujuan pendidikan.

Desain kurikulum pendidikan karakter bukan sebagai teks bahan ajar yang diajarkan secara akademik, tetapi lebih merupakan proses pembiasaan perilaku bermoral. Nilai moral dapat diajarkan secara tersendiri maupun diintegrasikan dengan seluruh mata pelajaran dengan mengangkat moral pendidikan atau moral kehidupan, sehingga seluruh proses pendidikan merupakan proses moralisasi perilaku peserta didik. Bukan proses pemberian pengetahuan moral, tetapi suatu proses pengintegrasian moral pengetahuan.

Penerapan pendidikan karakter pada kurikulum dapat dilihat pada porsi pelajaran agama yang menurut penulis cukup banyak dibandingkan sekolah umum. Pendidikan Agama Islam di Madrasah terdiri atas empat mata pelajaran, yaitu: Al-Qur'an-Hadis, Akidah-
Akhlak, Fikih, dan Sejarah Kebudayaan Islam. Masing-masing mata pelajaran tersebut pada dasarnya saling terkait, isi mengisi dan melengkapi. Al-Qur'an-hadis merupakan sumber utama ajaran Islam, dalam arti ia merupakan sumber akidah-akhlak, syari'ah/fikih (ibadah, muamalah), sehingga kajiannya berada di setiap unsur tersebut. (Permenag No 2 tahun 2008). Kurikulum formal yang baku tersebut masih ditambah lagi dengan beberapa materi agama yang menunjang kurikulum formal, yakni muatan lokal seperti ibadah kemasyarakatan, tahfiz al-Qur'an dan lain-lain.

Pada beberapa madrasah yang memanfaatkan peluang-peluang belajar di luar kelas sebagai wahana pengembangan pendidikan, kegiatan ektrakurikuler juga muncul sebagai keunggulan tersendiri yang pada giliranya melahirkan kredibilitas tersendiri bagi lembaga. Tidak jarang kita dengar alasan-alasan orang tua dalam memilih sekolah sebagai tempat belajar anaknya atas dasar pertimbangan mereka terhadap sejumlah kegiatan di luar kegiatan tatap muka di kelas. Dengan demikian, kegiatan ektrakurikuler dapat dikembangkan dalam beragam cara sebagai media pendidikan karakter. Penyelenggaraan kegiatan yang memberikan kesempatan luas kepada pihak madrasah, pada giliranya menuntut kepala madrasah, guru, siswa dan pihak-pihak yang terkait untuk secara efektif merancang sejumlah kegiatan sebagai muatan kegiatan ektrakurikuler berbasis pendidikan karakter.

Adapun terkait dengan pendekatan yang kedua, dimana pendidikan karakter tidak secara langsung dimasukkan ke dalam kurikulum formal, melainkan berlangsung alamiah dan sukarela, maka tugas madrasah menciptakan kondisi yang kondusif untuk teaktualisasinya nilai-nilai akhlak mulia dalam interaksi kehidupan di madrasah. Untuk hal ini maka komponen perangkat madrasah dalam hal ini Kepala Madrasah, Guru, Tata Usaha dan Majelis Madrasah memegang peranan yang strategis.

\section{SIMPULAN}

Pendidikan karakter dapat dimaknai sebagai pendidikan yang menekankan pada 
pembentukan (internalisasi) nilai-nilai positif (akhlak karimah) pada setiap anak. Pendidikan karakter merupakan wahana menanamkan nilainilai kebaikan kepada anak baik dari aspek kognitif, afektif maupun psikomotor. Salah satu lembaga pendidikan yang memberikan perhatian besar terhadap penanaman nilai karakter anak adalah Madrasah yang memiliki ciri khusus yang membedakan dari sekolah umum yang lain. Penanaman nilai karakter di Madrasah dapat dilihat dari porsi kurikulum agama yang cukup besar baik dalam kurikulum formal maupun kurikulum non formal. Oleh karena itu Madrasah bisa menjadi alternative solusi yang sangat tepat dalam mewujudkan pendidikan karakter sesuai dengan yang diprogrmkan oleh pemerintah dewasa ini.

\section{DAFTAR RUJUKAN}

Arismantono, 2008. Tinjauan Berbagai Aspek Charakter Building: Bagaimana Mendidik Anak Berkarakter, Yogyakarta: Tiara Wacana.

Chabib Thoha, dkk. 1996. Refolmulasi Filsafat Pendidikan Islam, Yogyakarta: Pustaka Pelajar.

Hernowo, 2004. Self Digesting; Alat Menjelajah dan Mengurai Diri, Bandung: Mizan Media Utama.

Imam Ghazali, tt. Ihya Ulumuddin Jilid III, Beirut: Dar al-Fikir.
M. Anis Matta, 2006. Membentuk Karakter Cinta Islam, Jakarta: al-I'tishom Cahaya Umat.

M. Zulfajri dan Ratu Aprilia Senja, 2003. Kamus Lengkap Bahasa Indonesia, Jakarta: Dhifa Publisher.

Permenag No 2 tahun 2008.

Nurcholis Majid, 2000. Masyarakat Religius; Membumikan Nilai-Nilai Islam Dalam Kehidupan Masyarakat, Jakarta: Paramadina.

Raymond J Corsiny, 1994. Encyclopedia of Psichology, United State of Amerika: Intercience Publication.

Sanjaya, 2010. Kurikulum dan Pembelajaran, Jakarta: Kencana Prenda Media Group.

Thomas Lickona, E Shapes dan C. Lewis, 2003. CEP's Eleventh Principals of Effective Character Education, Washington, Character Eduaction Patnership.

UU No. 20 tahun 2003

Zubaidi, 2011. Desain Pendidikan Karakter, Jakarta: Prenada Media Group. 